\title{
Schooling for a Stateless Nation: The Predicament of Education without Consensus for Karen Refugees on the Thailand-Myanmar Border
}

\author{
Subin Sarah Yeo, Terese Gagnon, and Hayso Thako
}

\begin{abstract}
This article addresses the issue of schooling for refugees, as members of a stateless nation, in the context of Karen refugees in Thailand. The authors used ethnographic methods of in-depth, semi-structured interviews and participant observation with over 250 residents of Mae La refugee camp. Our conceptual framework draws on theories of pedagogy for liberation and grassroots development. We found that, due to overlapping sources of authority with divergent visions of the future for refugee learners, the existential crisis of being members of a stateless nation is the most pressing issue for education to address. We suggest that a top-down approach to refugee education relying on technical solutions, while ignoring issues of history, power, and meaning-making, will ultimately fall short of being fundamentally transformative.
\end{abstract}

Keywords refugee education, Karen refugee camp, Thailand-Myanmar border, ethnography, grassroots development

\section{Introduction}

Because assistance in [refugee camps] focuses on keeping people alive, relief is often described as an apolitical humanitarian project. But refugees by their very nature are the products of a struggle over power and authority-that is, a product of politics. Nowhere is this more evident in relief programs than in the provision of schools (Waters and LeBlanc 2005, 39).

It has long been a neglected priority of global society to cater to the educational needs of refugee children in the context of developing countries (Dryden-Peterson 2017). To explore this problem within the global policy agenda of international education and development, it is imperative first to define who is counted as a 
refugee and how refugees have been perceived. According to UNHCR (2010), refugees are defined as people who have crossed an international border due to well-founded fear of persecution. Although international conventions, such as the 1951 Refugee Convention, and the 1967 Protocol, provide international norms declaring the rights of refugees and countries' obligations toward them, the realization of the right to education varies in each nation-state. Despite the fact that 144 nation-states are currently party to the Convention, there are notable exceptions among countries in the Global South, where 86 percent of refugees end up living while seeking their first asylum. Thus, in many developing countries that are not party to the global Convention the rights of refugees are not bound by the Convention. However, these rights are often provided for anyway, in a fashion similar to what is called for in the Convention.

Under these circumstances, various transnational bodies have developed a global agenda for refugee children to be effectively integrated into the host countries through education. However, many host countries still deny access to public schooling for would-be refugee students. This tension between global rights discourse and its realization in national and local contexts results in the dark irony that many refugee children are trapped in a precarious place between transnational and national policies, particularly in the domain of education. In short, the global rights agenda mandates the integration of refugees through inclusive education policies. Yet, the refugee children, who are in effect under the national policies of host countries, lack the status that would enable their future economic, political, and social participation in the same host country for which education has sought to prepare them (Dryden-Peterson 2016; Waters and LeBlanc 2005).

It is crucial to emphasize the fact that every refugee camp has its own context and distinct characteristics, influenced in part by the nation and region in which it is located. Starting from this understanding, we, the authors, have conducted a qualitative case study by focusing on the predicament of education in a majorityKaren refugee camp (technically a "temporary shelter") in Thailand: Mae La Camp. Mae La is one of the largest and oldest refugee camps in Asia. Though Thailand's government has not ratified the Refugee Convention, since the 1980s it has been providing sanctuary to refugees by allowing local and international organizations to operate in the camps. While Global North nations that are party to the Convention often decry the lack of participation by Global South nations, such as Thailand, we recognize that the situation is complex. As Carrie Perkins (2019) notes, Thailand and other historically non-aligned nations have resisted signing the Convention out of concern that doing so would facilitate interventionism into their national affairs on the part of more powerful nations via international bodies. Meanwhile, many of these host nations have come together to create their own standards for the treatment of displaced persons; these are enshrined in the Bangkok Principles, with forty-seven member states. Although this agreement 
puts forward many of the same goals as the Refugee Convention, the value of this agreement is arguably underappreciated by powerful nations that still pressure Global South countries to be party to the 1951 Convention (ibid., 59-62).

Various transnational actors have been providing essential services in the refugee camps in the areas of health, food, shelter, and education as a form of humanitarian relief. One of the notable features of education in the Karen refugee camps, located on the border of Thailand and Myanmar, is that the system of schools and learning is structurally designed, staffed, and managed by residents of the camp, who are themselves refugees, with financial support from external stakeholders (Oh 2011). In most other cases, refugee children follow the host country's national curriculum or the curriculum of their country of origin. However, the Karen refugee camps are a fertile site of investigation because the curriculum does not derive from either Myanmar or Thailand (UNESCO 2018). Karen refugees brought their own education curriculum to the camps on the border in Thailand, and a substantial number of children in the Karen State on the Myanmar side of the border are also taught according to the same curriculum, under management of Karen National Union (KNU). However, there are numerous restrictions imposed by the Thai government on the movement, livelihoods and education of camp residents. These formidable restrictions have significant implications for their personal and social development, as well as for the development of the refugee population at large. Most students within the Karen education system, both in Karen State and in the refugee camps, are unable to speak the Burmese language fluently, or to integrate with the Myanmar government's education system. They are oriented towards a Karen national identity, rather than Myanmar citizenship (South and Lall 2016).

In this unique context, our research purpose is to delineate the local perspectives on the meaning of education for Karen refugees as members of a stateless nation. By adopting an ethnographic approach as a primary research method, we ask: (1) What is the meaning of education for Karen refugees? (2) How is education provided, managed and accredited? (3) How does the educational predicament in the camp relate to the intersection of history and politics of Karen people in Myanmar? Our study describes ethnographically the educational predicament in Mae La refugee camp in order to analyze local perspectives on issues regarding educational sustainability as a stateless nation, in partnership with humanitarian actors. We draw on a conceptual framework of post-development perspectives related to the practical field of schooling for refugee learners inside the camp. To do so, we initially provide a brief summary of recent frameworks for refugee education worldwide. Then we describe the current status and distinctive features of education in Mae La camp, by questioning Eurocentric tendencies of traditional development approaches to refugee education. 


\section{Literature Review: Refugee Education Worldwide}

Prior to exploring the case of Karen refugee education in Thailand, it is vital to understand the trend of refugee education worldwide. Under the United Nations Sustainable Development Goal 4-to ensure inclusive and equitable quality education for all-refugee children hold a right to access quality education. Nevertheless, international organizations, state governments, and non-governmental organizations (NGOs) together face complex challenges in improving access to, and quality of, education for refugee children. Since World War II refugee education has served different purposes at different points in time. Jones and Coleman (2005) explain that the needs of refugees were at the forefront of the work of the nascent United Nations (UN), when it took on educational responsibilities in the post-war European refugee crisis and then in emerging Cold War conflicts and independence movements. At that time, the nature of conflict was not bounded by battlefields, but conflicts were more dangerous for civilians and they led to rapidly growing refugee populations, including child refugees (DrydenPeterson 2016). Initially, the United Nations Educational, Scientific and Cultural Organization (UNESCO) was the global institution that held the mandate for refugee education. However, later the UN High Commissioner for Refugees (UNHCR) took on this responsibility, as its decentralized structure was wellsuited to the local provision of education for refugees who remained outside the purview of centralized planning for national education systems (Ruggie 2003). In 1967 UNHCR signed a Memorandum of Understanding with UNESCO and formerly took on the mandate for refugee education (UNESCO and UNHCR 1984).

As Table 1 shows, the means of refugee education have undergone distinct periods of change (Dryden-Peterson 2016). Specifically, prior to the mid-1980s the role of international organizations in the provision of refugee education was limited in scope. In this initial phase, the focus was on post-primary education through scholarships for an elite few. Later, schools created for refugees played a meaningful role in developing an overall strategy, with a clear vision for the connection of education in host countries to future participation in countries of origin. At this stage, refugee education was organized by local refugee communities; global stakeholders played only minor roles.

In 1985 a review of refugee education programs concluded that UNHCR would shift funding away from individual scholarships to support primary school children (UNHCR 1988). This shift was driven by national trends in developing countries on the movement for Universal Primary Education (UPE) and the wide consensus on the right to Education for All (EFA), reflected in the 1989 Convention on the Rights of the Child (UN 1989). Along with the development of EFA and the Millennium Development Goals, the normative shifts and formalization of commitments through conventions and declarations marked the 
Table 1. Means of Refugee Education

\begin{tabular}{l|l}
\hline \hline \multicolumn{1}{c|}{ Period } & \multicolumn{1}{c}{ Means of Refugee Education } \\
\hline Phase 1 (1945-1985) & Local Provision Meets Global Institutions \\
\hline Phase 2 (1985-2011) & Global Governance of Refugee Education \\
\hline Phase 3 (2012-present) & Global Support to National Systems \\
\hline
\end{tabular}

Source: Adapted from Dryden-Peterson (2016)

development of new forms of global authority in education. Refugee education was clearly under the mandate of a UN agency, outside of the structure of any nation-state. Hence, global, top-down movements had strong influence on local provision of education and nation-states were not considered key stakeholders (Dryden-Peterson 2016). This was because the service provision of education outside the nation-state structures was possible through refugee camps. During this phase, large refugee camps were formed in Thailand, Pakistan, and eastern Democratic Republic of the Congo. Refugee camps were favored by UNHCR for reasons of efficiency in delivering services to large refugee populations, and by host governments for reasons of security and allocation of financial responsibility for refugees to the global community while avoiding interventions from nationstates (Verdirame and Harrell-Bond 2005). Thus, in Phase 2, it was necessary for refugee children to be educated separately as UNHCR policies primarily focused on utilizing education to facilitate a swift return and enable future participation in the country of origin (UNHCR 2003). With institutionalization of global influences on refugee education in this phase, international agencies acted as "pseudo-states" for refugees (Waters and LeBlanc 2005). Many scholars highlight the fact that by the mid-1990s refugee education was led by policy only, not by people (Dryden-Peterson 2016; Kelley et al. 2004). For instance, UNHCR did not have a single education officer working in a refugee-hosting country between 1998 and 2011, and it resulted in a total lack of expertise. UNHCR outsourced the provisioning of refugee education to other implementing partners, including national and international NGOs, who were paid to deliver education to refugees inside camps. Throughout this phase, UNHCR measured quality of education merely by inputs: for example, number of pupils per teacher, and the percentage of teachers who were trained (Dryden-Peterson 2016).

Phase 3 began in 2012, when the UNHCR released its Education Strategy. With this, the primary responsibility for refugee education shifted from transnational to national. This strategy emphasized "integration of refugee learners within national systems" (UNHCR 2012, 8). This major shift happened for several reasons. First, the provision of separate schooling was impractical since more than half of refugees lived in urban areas outside camps (UNHCR 2009). Second, it was realized that the nature of conflict was long-term, and that 
refugee children would likely spend the entirety of their school-age years in host countries. Third, there was a need to share the financial burden of supporting refugee education over an extended and unknown period. By 2016 the UNHCR had formal relationships on refugee education provision with the national education authorities of its twenty-five expanded priority country operations. This formal relationship enabled the negotiation of access to national schools for refugees, and established means of coordination. While historically refugees had been absent from national development plans and education sector plans, some countries began to include refugees in provincial and national planning documents (Dryden-Peterson 2016).

Since refugee education has recently entered a new phase in which global actors rely upon national integration rather than global governance, it is imperative to examine refugee students' educational experiences in practice, as these may fall in conflict with the discourse of inclusion for countries of the Global South. Global actors have gradually changed their role from that of "pseudo-state" (Waters and LeBlanc 2005) to "global supporter," and most recently to advocate for national education systems to include refugee learners. This variation seems to push for education to contribute to refugee students' inclusion in national education, as well as for their integration into the host society (de Wal Pastoor 2016). In this context, the current challenges are undeniably complex, due in part to the tensions between stakeholders on the global, national, and local levels. To understand this paradox more clearly, we adopt an interdisciplinary perspective, integrating insights from the fields of international development and education.

\section{Research Design: Concepts and Methods}

\section{Conceptual Framework: Post-Development Perspectives in Education}

Such a shifting of global paradigms for refugee education, as has just been discussed, parallels in many ways the regime changes that residents of Myanmar have experienced through shifts from monarchy, to colonialism, and then to nationalism in the last century and until now (Thant 2001). Changing tides of governance-and with them new polices to comply with-is a phenomenon experienced by local people in many parts of the world. This is perhaps especially pronounced in those countries of the Global South where international humanitarian organizations exert a strong presence, often with highly changeable goals and standards-as discussed in the previous section-that reflect the assertion of soft power (Falk 2015). To say that these "regime" changes can be disorienting to the lives of ordinary people is an understatement. Yet, from one mode of governance to the next, too often many of the same social problems persist, such as poverty and lack of access to quality education. At a fundamental level, this generalized lack of substantive change, coupled with an overabundance 
of superficial change that comes with shifting regimes, stems from the way in which governance is most commonly approached: top-down, from the global and national level, versus bottom-up. Starting from this understanding, and building on what many scholars, activists and ordinary people have previously stated, we assert that top-down paradigms of refugee education have failed to produce the needed results. This is because such approaches, which rely on "technical solutions" (Dunn 2017, 25), do not address the fundamental existential crisis experienced by members of stateless nations.

Even beyond the refugee context, in recent decades there have been extensive critiques levelled at top-down approaches to international development (Escobar 2012; Ferguson 1994; Shiva et al. 2000). Such critiques of the imperialist, neoliberal, and Eurocentric nature of development paradigms have their origins both inside and outside of the academy. Indigenous communities have long criticized the oppression and hegemony enacted by so-called development initiatives, often linked to settler colonialism (Simpson 2014; Stevenson 2014). The justifications for such colonial and neo-colonial projects have been rooted in Enlightenment thinking and a faith in market growth. Anthropologist Arturo Escobar $(2010 ; 2012 ; 2018)$ has been a vocal critic of traditional development and is a leading proponent of post-development theory and praxis. Emphasizing epistemologies of liberation, his work intersects with critical theorist Paulo Freire's $(1996 ; 2004)$ writing on education as emancipatory practice. Here we are interested in how post-development thinking, such as that laid out by these two scholars, can provide insight into the persistent shortcomings of current approaches to refugee education as development, and how it may offer some insights for alternative ways forward. Indeed, Escobar and Freire have not only critiqued what they see as flaws in the current oppressive system, but they have also offered their own visions_-if tending to be overly general—of what a different approach would look like. On the broadest level their visions underscore the importance of relationality, dialogue, conscientization, and grass-roots action as a counter to the embedded framework of rational individualism that has tended to undergird traditional development and Euro-American education systems alike (Escobar 2018; Freire 1996).

The global spread of traditional development paradigms has been facilitated in part through education. Likewise, it is through education systems that such ways of thinking can be challenged and potentially transcended. Educational institutions are essential to perpetuating the current paradigm or, alternatively, being at the forefront of what Escobar (2015) refers to as "the transition" to new modes of thinking and being, described as degrowth or post-development. This is where Freire's understanding of education as a tool for transcending oppression comes into play. His approach to education aims to transform oppressive structures through conscientization and dialogue, against the idea of banking education for learners to conform with the social orders. Thus, as a conceptual 
framework for this article we apply post-development thinking to the problems at hand in schooling for refugee children and young adults in Thailand, as a case study for refugee education more broadly. We suggest that this application of post-development theory can shed new light on why it is that changing paradigms of governance have, until now, largely failed to produce transformative results for refugee teachers and learners. Additionally, we begin to imagine what alternative, bottom-up approaches might be possible. Finally, and crucially, we highlight the fact that not only do we draw on these concepts as external researchers, but we also note that post-development perspectives and Freire's critical theory are integrally employed by leaders and teachers within the Karen education systems in the refugee camp we describe. Our engagement with these schools of thought is very much dialogical and intersubjective. It is born out of the enduring relationships we have with our research collaborators, many of whom are highly invested in theorizing these issues and searching for transformative solutions: solutions that lead towards freedom.

\section{Methods}

The authors of this paper view this project as a case study addressing refugee education more broadly. We conducted our field research using ethnographic methods of in-depth, semi-structured interviews and participant observation, all carried out in Mae La camp between 2017 and 2019. Qualitative data in the form of audio recordings, transcripts of conversations, and field notes have been analysed and synthesized into general observations. Although our fieldwork research was conducted separately_-but during overlapping periods of time, and in dialogue with one another-this project has been highly intersubjective, growing from a shared focus on the conceptual basis of post-development thinking. The original contributions of this article have all emerged collaboratively from discussions between the authors over a sustained period of time, from February 2018 to November 2019. The research draws on a broad sample size of research consultants and countless hours of formal recorded interviews as well as informal conversations and experiences in the form of participant observation, as are characteristic of ethnographic methods. Combined, we spoke to over 250 individuals in Mae La camp. Collectively we have recorded over forty-eight hours of interviews and accumulated a combined ten months of full-time research while living in Mae La camp. This combined experience represents a unique perspective on life in the camp, informed by a level of everyday familiarity and depth of connections that is not often possible for researchers. Although we draw on a very broad base of data and experience, in this article we highlight the voices of a small number of key research collaborators whose words especially powerfully expressed sentiments we heard voiced again and again across multiple interviews. Thus, the quoted passages shared here are ones that are representative of much wider patterns we found in the research data. 
Table 2. List of Key Research Participants

\begin{tabular}{c|c|c|l|l}
\hline \hline No. & Age & Gender & \multicolumn{1}{|c}{ Occupation } & \multicolumn{1}{|c}{ Location of Interview } \\
\hline 1 & $50 \mathrm{~s}$ & $\mathrm{M}$ & Educational Leader & Karen State \\
\hline 2 & $40 \mathrm{~s}$ & $\mathrm{M}$ & Community Leader A & Interviewee's house \\
\hline 2 & $60 \mathrm{~s}$ & $\mathrm{M}$ & Former Head & KECD $^{\mathrm{a}}$ office \\
\hline 3 & $20 \mathrm{~s}$ & $\mathrm{~F}$ & Student A & College Campus, Mae La Camp \\
\hline 4 & $20 \mathrm{~s}$ & $\mathrm{M}$ & Student B & College Campus, Mae La Camp \\
\hline 5 & $20 \mathrm{~s}$ & $\mathrm{M}$ & Student C & College Campus, Mae La Camp \\
\hline 6 & $30 \mathrm{~s}$ & $\mathrm{~F}$ & Teacher Trainer & KRCEE ${ }^{\mathrm{b}}$ office \\
\hline 7 & $40 \mathrm{~s}$ & $\mathrm{~F}$ & Staff & KRCEE office \\
\hline 8 & $40 \mathrm{~s}$ & $\mathrm{M}$ & Community Leader B & Interviewee's house \\
\hline
\end{tabular}

Source: Authors

Notes: a. Karen Education and Culture Department

b. Karen Refugee Committee Education Entity

Out of concern for the privacy and well-being of our interlocutors, all names of individuals and schools have been changed or omitted. Additionally, some personally identifying information has been changed, in spite of the fact that many of our research collaborators expressed the wish that we use their real names in our report. Because Mae La camp is a relatively small society, there are serious issues for ensuring the plausible deniability of our research collaborators' identities. Therefore, we have also chosen not to share detailed biographical information about the key research participants whose voices are highlighted in this article. Nonetheless, in the interest of transparency, Table 2 provides some context for the individuals quoted in the text. Again, while this itself is a small number of individuals, it is representative of the qualitative data collected from the over 250 people whom we interviewed.

\section{Characteristics of Education in Mae La Refugee Camp}

\section{Historical Context}

To understand how schooling is provided for residents of Mae La camp, and why education remains so critically important to many Karen refugees, we contextualize their educational predicament within the broader context of Kawthoolei (the Karen homeland) as a stateless nation. To this end, we include insights from the Karen Refugee Committee, and describe historical factors that have led to displacement. Taken together, these aspects of history and identity 
help to delineate why education remains as a point of pride, and even a means of cultural survival, for Karen in exile. Approximately 85 percent of the refugees in Mae La camp are of the Karen ethnic group from Myanmar who have fled to Thailand due to civil war. This seventy-year-long civil war-begun in 1949 and currently the longest war in the world-has been fought between the central Myanmar government and Karen revolutionary armed groups. Most notably these Ethnic Armed Organizations include the Karen National Liberation Army (KNLA) - the armed branch of the KNU-and the Democratic Karen Buddhist Army, a splinter group of the KNLA, which broke off in 1994 and joined the Myanmar military. Many Karen who fled to Thai refugee camps to escape the armed conflict brought along with them their education system, and have continued to develop it in exile since the 1980s. This led to the formation of an educational entity, in 2007, under the management of the Karen Refugee Committee, known as Karen Refugee Committee Education Entity (KRCEE). Below is a very brief overview of this history (pre-independence to present) as it relates to Karen education.

After gaining independence from colonial rule by the British in 1948, Myanmar (then Burma) ${ }^{1}$ developed a robust education system that reflected the nation's diverse roots. It included traditional Buddhist temples, British colonial schools in the lowlands, and Christian missionary schools established in Karenmajority areas, including in the southeast of the country. Formal Karen education was first established even earlier, in 1854, in Irrawaddy by the American Baptist Missionaries. The school of the highest level was opened at Koesue in 1854. The first Karen institute was established in 1858 as Bassein Sgaw Karen Normal and Industrial Institute teaching English, Bible, mathematics, geography, history and health, along with industrial and housekeeping subjects (Pwe 2018). By the time of Myanmar's independence in 1948, there was a network of primary schools teaching basic literacy in Karen language and using English as the medium in secondary schools. These schools were founded across the southeast of Myanmar, in the area that is today referred as Karen State (Rebecca 1989). Due to this activity by missionaries, and the fact that Karen communities had been especially receptive to Christianity, in comparison with the ethnic majority Bamar people and members of other ethnic minority groups, the Karen were considered an especially well-educated and relatively large minority group around the time of independence. However, in the view of some Karen, including one leader in Karen education who was interviewed, independence was the beginning of the end for Karen education in Myanmar. In an interview, this leader stated:

This is just my own analysis, you will not find this in any book: but from what I see, in 1948 when Burma gains its independence, starting then the Karen begin losing all their rights and privileges up until now... Not only do they lose their human rights and privileges, but they are forced to become refugees... Because they don't get their 
own rights and what they claim for their own nation, the Burmese forced them to become rebels in 1949 until now (Interview with Educational Leader).

While this analysis may be debated by some historians, it is widely agreed that the 1960s marked the beginning of an escalated and brutal phase in the Myanmar military's tactics in suppressing dissenting ethnic minority groups. Most notably this included, in the mid-1960s, the start of the hpyat lay hpyat, or "Four Cuts," strategy that was aimed at cutting off the flow of funds, food, intelligence, and recruits to rebel-controlled areas (see Ferguson 2014, 297; Fink 2009, chap. 2; Smith 1999, 259). Such tactics were not limited only to the military realm and battles over territory, but also included struggles over cultural and ideological domains, including education. According to Ashley South (2011), after 1962, due to the introduction of the "Burmanization" policy by the central Myanmar government, the Karen education system was dismantled. The Karen who lived in the eastern regions of the country, bordering Thailand, tried to retain the previous education system, which was administered by the Karen Education and Culture Department (KECD), one of the departments of the KNU, outside the supervisory purview of the Myanmar government. ${ }^{2}$ Beginning in the 1990s, when large numbers of displaced Karen were first forced to flee across the border to Thailand, they brought this structure for Karen education with them. It is a testament to the significance that having their own education system holds for Karen refugees that they managed to construct schools and train teachers in the midst of coping with exile. These educational structures have remained strong in the camps until today, even growing in numbers served and curriculum offerings.

The Karen school system in the camps is believed to represent an alternative model, quite distinct from the state systems of Myanmar or Thailand (South and Lall 2016). The Burmanization policy, introduced under the Myanmar military government in 1962, marginalized ethnic minority languages, including Karen (World Education 2016). Ethnic Armed Organizations and civil society actors resisted this Burmanization through a number of strategies, including armed conflict and the development of education regimes that preserved and reproduced their languages and cultures under difficult circumstances (South and Lall 2016). ${ }^{3}$ Despite these formidable challenges, the Karen have maintained their education system under military rule for the last five decades. Although Karen education in the former Myanmar capital of Yangon has overall been weakened since independence, ${ }^{4}$ Karen education in parts of Karen State and in refugee camps in Thailand has remained strong overall. This is due in large part to the ideological freedom-in terms of expressing Karen culture and a desire for autonomywhich these spaces allow, in comparison to strictly government-controlled areas within Myanmar. ${ }^{5}$ This is illustrated in the statement from a Karen community leader living and working in Mae La camp. He asserts that in order to understand Karen identity in exile it is first necessary to consider the past: 
The first part is history: the history of what they have been going through, the trials, the difficulties in life. So, because of the history, I can see that the Karen, even though they are staying in different places, and different countries, and the refugee camp, their minds, their thinking stays fresh. They are the Kawthoolei, or the Karen people who belong to Kawthoolei (Interview with Community Leader A).

In addition to space for the open expression of ideology and identity, another advantage that Karen schools on the border enjoy is that they benefit from donated materials as well as volunteer teachers that can reach these areas more easily than inside Myanmar. These Karen schools are known to be well organized and managed, as they attract students not only from the Thai-Myanmar border, including refugee camps in Thailand and Karen State in Myanmar, but also from as far off as Yangon, Irrawaddy, and Thanitharyi divisions of Myanmar. There is irony in this because such schooling is not externally recognized as formal education. This lack of formal recognition is due, in part, to the fact that under Thai law, these camps are not recognized as refugee camps but rather as "temporary shelters," even though they have been in existence for over thirty years.

\section{Education as a Point of Pride and Identity}

Considering these historical factors, alongside reoccurring narratives heard from research collaborators about the importance of education for the continuation of Karen identity, it seems that Karen refugees view education as a point of pride and a last resort for sustaining national identity. Despite the absence of a modern state system-and even of physical territory in the case of displaced personsKaren in exile sustain their language, history, and culture through the practice of education. Illustrative of this sentiment that was widely expressed by those we spoke with, the former head of the KECD states:

The students, camp populations, are the national hope for Karen.... Our focus is to educate our young generation to become caring and competent citizens. Also, to be part of their society and maintain their culture. I think that's the main focus of our education. I don't know how important it is. For us, we strongly believe that without maintaining our culture, heritage, language, through education for our younger generation, that there is a threat that Karen people will be demolished or vanished from the country. Because the aggression that we face, from other ethnic nationalities, especially from the Burmese, it is very real to us; that if we don't prevent that, we will easily be wiped out, all generations.... We try to engage with the ruling government in Burma, but they are very centralized still. For us to say that you will have better opportunity when you come back to Burma from the camps, that will be a false hope. We don't want to give false hope or guarantee to the camp residents (Interview with a former head of KECD).

Not only the education leaders, but the students in the camp also regard Karen education as a point of pride. A dialogue with a Karen refugee student 
about her previous educational experience in Myanmar demonstrates how the government schools focus heavily on rote-learning, and ethnic minorities are excluded.

I asked this student what the Myanmar government schools were like and she demonstrated for me: crossing her eyes and looking like she was in a trance, nodding and snoring and acting like a zombie. Then she proceeded to describe how her experience of the "Burmese" government school in her area was one of rote learning and having to follow strict standards of behavior, while not really learning anything at all. She further described how it was hard for her to go to school because her family was poor (and needed help from her and her siblings) and they had to walk a long way to get to the school. Often, the school fee and costs of uniforms or materials, as well as distance, make Myanmar government schools inaccessible to students. For Karen students, added to this is discrimination and exclusion based on their identity. This discrimination and exclusion often manifested itself in "mysteriously" not passing the final exam of high school which was required to graduate after years of study and expense. With this kind of discrimination, one wonders why anyone would put in the effort to attend school at all (Fieldnote taken by the Author).

This outline of Karen education critically demonstrates that the education in the camps is not provided in a form of education in emergency, as in other refugee camps. With a long history of running their own education system as an ethnic minority in Myanmar, the education system in the camps is run in a systematic and organized manner, although it accommodates the participation of external partners in various ways (Lee 2007). This provides some insight into how it is that a nation without an internationally recognized state and territory, and with hundreds of thousands of its members living in global diaspora, can persist and, in terms of identity, even thrive. As the formerly quoted Karen educational leader states, reflecting on the importance of education for Karen identity: "I feel that I have the obligation; I believe that I need to do something for my people before I die. Out of many things I pick up, I see that the best thing, so as not to lose our identity or our freedom or our human rights, $[\ldots]$ that I need to do for our people is education." This quote reflects that education is seen as especially crucial for a nation without a territory because it provides a space where history and meaningmaking can be reconciled in a way that coheres into shared understanding. While there is certainly the danger of re-entrenched nationalism being the outcome of such an approach to education, we argue that depending on how these issues are grappled with, and what nuance of understanding is shown by teachers and educational leaders, this need not necessarily be the case. Further, we argue that a curriculum and an approach to daily struggles of life that ignore such pressing existential issues do nothing to resolve the fundamental conflict, but only delay or exacerbate it. 


\section{Structure of Education System under the Pseudo-State}

KRCEE is the education department that manages the affairs of the Karen refugee camps in Thailand. One of the notable features of education in the camps is that the system of schools and learning was set up, staffed and managed by the refugees residing in the camps, with financial help from external organizations. The camps are under the authority of the Thai Ministry of Interior, and funded through donations coordinated by UNHCR, but administered by international NGOs working for the camps. For the seven Karen refugee camps along the border, the most recent record indicates that there are twenty-six KRCEE staff managing a total number of sixty schools, with 841 teachers and 17,103 students from primary to post-secondary school level (KRCEE 2019). Higher education programs-post-12 schools-play an important role in the camps, as most students could not continue their higher education after high school. Currently, there are fourteen higher education schools with 1,067 students and 153 teachers (ibid.). Among the seven Karen refugee camps, Mae La refugee camp is the largest camp with 30,579 residents (TBC 2019). It has twenty-three schools, from primary to post- 12 levels, staffed by 357 teachers and with 6,284 students (KRCEE 2019). In order to implement and manage the daily activities of camp education, the Office of Camp Education Entity (OCEE) was formed by KRCEE as a central administration. OCEE has forty-nine staff, managing and implementing camp-based educational activities (OCEE 2019). OCEE staff help to organize educational activities, such as school inspections, teacher trainings, monitoring, and reporting to KRCEE. It also supports the organization of important education-related events, such as World Teacher's Day, World Refugee Day, and other social events as necessary.

\section{Teacher Training, Curriculum, and Examination}

Basic teacher training for Karen schools is offered inside the refugee camps. Teachers can use their credentials gained from these training programs in KRCand KNU-administered schools in Thailand and Myanmar. The basic training program consists of one-time teacher training sessions organized twice a year for in-service and pre-service teachers. Additionally, subject content training is also provided once a year to help the teachers feel more competent in their teaching. KRCEE, along with the international NGOs providing education services, helps to organize the trainings with the support of OCEE staff. Higher education teacher trainings are provided upon the request of schools, but most of the time the teacher trainings are self-organized to meet the teachers' own needs. Some of the trainings commonly requested by the higher education schools are for curriculum development, classroom management, lesson planning, and financial management. Due to limited time and resources, the trainings are usually conducted for only one or two days.

The curriculum used by Karen schools in the refugee camps in Thailand 
is different from that used by the schools in Karen State, run by the Myanmar government, and the ones used by the local schools run by Thai Ministry of Education. Since 2008 the camp's education system has been standardized, with new curricula at KRCEE being designed and supported by Karen education stakeholders and international NGOs providing services to refugee education. The curriculum is designed to promote critical thinking and uses student-centered pedagogy (KRCEE 2008). From primary to post-12 schools, Sgaw Karen is used as the language of instruction. Burmese language is taught as a separate subject, as is English. Additionally, in some schools, Thai language is taught as an extracurricular subject. Thus, in the primary education program, the subjects taught are Karen, English, Burmese, mathematics, science, geography, history and Thai (optional). In the higher education program, the curriculum is divided into two parts: Institution of Higher Education (IHE) curriculum designed by KRCEE, and non-IHE schools. The latter use an independent curriculum, and the medium language of teaching is mostly English. In higher education the history taught in the camps primarily covers Karen history, literature, poetry, and world history. This is not something that schools in Karen State run by the Myanmar government provide, as history there is perceived differently from the Karen and takes precedent in government schools of Myanmar. This creates two different understandings of Myanmar and Karen history, much of which is contradictory (Metro 2006).

Academic evaluation is conducted by KRCEE using the board exam for Grade 9 and 12. KRCEE is responsible for evaluating the results of the examinations. Students failing to sit for the board examinations are not allowed for reexamination unless with reasonable excuse. Any student who wishes to continue studying at the higher education level is required to pass an entrance test, which is conducted after the school board exam is successfully completed. English, mathematics and general knowledge are considered important subjects in order to pass the entrance test. There is some progress towards certifying the learning in the camps so that graduates can apply for further study in Thailand, Myanmar, or overseas in the future. Accreditation is inevitably restricted by the reluctance of the Myanmar and Thai governments to recognize a non-state entity. A framework of cooperation with the Office of the Vocational Education Commission, under the Thai Ministry of Education, was signed a few years ago with accreditation as one of the objectives. Although the Thai government is not a signatory to the 1951 Convention relating to the status of refugees, it does provide some form of sanctuary to the refugees and allows local and international organizations to operate in the camps, including those delivering educational services (Oh 2011; ADRA 2016). Thus, while there is a robust school system in the camps, the most urgent issue is that school completion certificates do not give graduates access to further educational opportunities in Myanmar or Thailand, and neither are their diplomas recognized for employment purposes. Understandably, this has created 
a longstanding struggle in the modern educational system.

\section{Predicament of Education in Exile: Education without a Modern State}

\section{Education without Accreditation: Education Recognized by Us, but not by Them} Regarding the ongoing issue of the lack of accreditation, Karen college students interviewed in Mae La camp articulated strong feelings about the direness of their situation. Many expressed feelings of frustration and apprehension at the uncertainty of their future after graduation. This situation represents a particularly striking and dark paradox because - as was mentioned previouslyyoung Karen people from inside Myanmar, and from various other camps and surrounding areas of Thailand, are coming to attend colleges in the Mae La camp since the institutions there represent the best, or only, option for higher education open to them. This is especially the case as colleges in the refugee camps work hard to keep their standard of education high, while keeping the financial cost and barriers to attendance low. They are also more easily able to connect with external sources of support-like church groups from the U.S. or Korea who offer financial support, and international volunteer teachers-than schools in Karen state in Myanmar. This phenomenon of being excluded from the education system in Myanmar, and thus having to seek out education in the camps, is illustrated in the life-history narrative of one student. She recounts:

I am the oldest of six siblings from a small village in brigade three where no one else speaks any English or Burmese.... My brother and I are lucky because, even though our parents have very little resources or education themselves, they told me [and my brother] "go, go," and sent us off [to the border] to get our education (Interview with Student A).

While most students interviewed expressed similar feelings of being extremely lucky or fortunate for the opportunity to gain education, this is not without considerable complexity.

The double bind that students face, as they indicated in interviews, is that they feel it would be either unsafe or futile for them to return home after completing their higher education degree. There are multiple factors at play here. First, to this day there is a perception among camp residents that returning to Myanmar after having spent time in the camp could place one at risk of being singled out by the military for retaliation. Second, the lack of accreditation for schools in the camp by non-Karen entities in Myanmar makes having the completion of a degree meaningless in term of opportunities for further education or professional employment. As one student explained in an interview, if they go back to their home in Myanmar the only option available to them, 
after completing a four-plus year college degree, would be to become a farmer. Evocatively, the student stated:

We have to spend the life of a refugee: we cannot move, we cannot stay here. I want to go back [to my village] but we cannot go back because of many problems.... If I go back, I cannot do anything: I have to become a farmer. Because here [in the camp] we graduated college and high school, but they didn't recognize us. They didn't recognize us, so we cannot do anything ... [even though] we already studied here for many years. So this is a big problem (Interview with Student B).

Later in the interview this student went on to express a sense of paralysis felt in the face of life in the camp-its present challenges-and uncertainty about what the future holds, sentiments common to many interviewees. Usually externally strong, and a leader among his peers, this student admitted to crying in bed many nights when thinking about the future. As he explained:

We stay here [in the camp] but everything is not okay, because we stand alone. Sometimes we think we have the "border problem" here, because here no one supports us. We cannot go forward, and we cannot go back; we have to stay here, stay in the dormitory. As [for] my purpose after graduating from [name of school], I don't know. Where will I be? Where will I go? Very difficult to make a plan. We cannot plan seriously, our own rights our own decision (Interview with Student B).

Such a critique of the conditions in the camp that make it impossible for one to decide one's own fate, to have autonomy, were echoed frequently by students and community leaders alike in interviews. Often, this lack of ability to "decide our own life" (Interview with Community Leader) was scaled up and down, from the individual, to the Karen refugee community at large by interviewees. In these conversations, interviewees acknowledged their need for the support of the UNHCR and NGOs operating in the camp, while also bitterly criticizing the effect that their over-determining force has on their ability to make choices and find meaning in their daily lives. In an interview, one teacher pointedly commented on organizations operating in the camp (and exerting their managerial power): "for humanitarian organizations, they can be so inhuman." However, alternative perspectives that noted the more positive aspects of humanitarian organizations and NGOs were also heard in interviews. One such example is a student who expressed a feeling of immense thankfulness for the presence of such organizations - even while hinting that they might commonly be seen as imperfect by camp residents-because without their aid, they and other refugees would be in an even worse situation. The student paused reflectively in the course of the interview, saying:

I just think that if there is no organization ... especially like NGO, if there is no ZOA, 
no Save the Children, we cannot get any education. We cannot get food or shelter. When I was a child, I remember that we didn't have any books to study, any pen, any pencil, any eraser.... Thanks to God for all the organizations! UNHCR too, right? I am so grateful for that. Because they came to help us, we can get education (Interview with Student C).

However, the same student also expressed the limit of this help. He went on to discuss how all the education they had received, which they were so grateful for, pointed to an uncertain outcome. This is due to the lack of accreditation of colleges in the camp that forecloses opportunities for students after graduation. There are few opportunities for work in the camp, and it is not generally possible for residents to leave to find work or seek further educational opportunities outside the camp. They explained their conundrum with sincerity and openness, stating, "After graduating from this college, I just plan to further my study in music. But where? There is no university where I have decided to go, because [there is] no more [financial] supporter ... no one to encourage me" (Interview with Student C). As the student expresses, lack of funding for further education is a significant barrier, but so is lack of legal documentation for many camp residents to leave the camp for more advanced study, and, just as significantly, lack of accreditation for schools in the camp that makes it difficult for students to gain acceptance to educational or professional opportunities outside the camp in the first place.

Figure 1. Students' Representation of Social Hierarchy in the Camp. Photo by Gagnon.

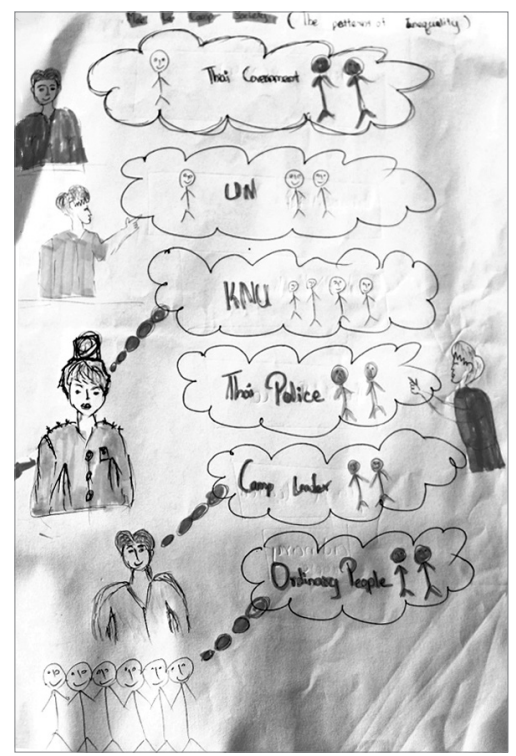

Students are far from naïve about the politics and organization of the camp and often delivered their own insightful explanations and analysis of how the camp functions. They pointed out the fact that people living in the camp who have a special title like "section leader," or those who hold a formal leadership position in schools, are able to move in and out of the camp, while their own movement is highly constrained. This is due to the fact that ordinary people are not allowed to leave the militarized camp unless having to go for an emergency visit to the hospital, which requires documentation in the form of a letter signed by the camp commander. Particularly interesting are the ways in which students understand the various actors in the camp-from UNHCR to the Thai Government and KNU-fitting together in a social hierarchy that results in 
the peculiar and total institution that is the camp. Figure 1 shows an image of a diagram created by college students in Mae La explaining their understanding of the power structure of the camp where they live. Such a visual representation lays bare the inherent tensions present in the camps, as the various actors have sharply contrasting visions for the camp, for refugees, and highly differential motivations for their own involvement. These same tensions, which make it difficult to delineate what a refugee camp should be, and whether it should even continue to exist, also make it extremely challenging to define education and its end goal within the context of this liminal, non-state space.

\section{Education Evaluated without a Consensus: Dilemma in What to Teach and How to Teach}

While it is challenging in the camp to define the rationale behind education, and its end goal, it is thought-provoking to investigate how teaching and learning are evaluated. As mentioned previously, examinations are conducted by KRCEE as part of the standardization of the school system along with other camps on the Thai-Myanmar border. Although KRCEE is an independent education department in charge of managing and evaluating education for the refugee learners within the camps, it is recognized neither by Thailand nor Myanmar's education departments. Therefore, evaluation results are only applicable within the camps, leaving the students who successfully graduate from refugee camp schools with no opportunity for further studies or career selection in the modern state systems. Meanwhile, the international NGOs providing financial support and working in partnership with KRCEE have their own evaluation criteria for their education projects involving teachers and students. Refugee teachers and community leaders often face the dilemma of how to balance the requirements from external actors with the beliefs they have about what students need in their mundane life. Teacher trainers from KRCEE expressed the opinion that substantive solutions for the daily struggles of the in-service teachers with this on-going dilemma must be treated as a priority by the external actors in order to properly meet local needs.

Teachers have a big dilemma in what to teach and how to teach.... Currently, it is hard for us too. Usually we have partners who work with us from NGOs. When they provide funding, they are also involved in training. In terms of activities, we would like to do our own monitoring and activity planning, but is it is hard for us. OCEE may have a different opinion about this, but it is hard. NGOs give the funding, but I don't think they are interested in how to solve the Karen teachers' struggles and dilemmas (Interview with Teacher Trainer).

For the locals who unexpectedly ended up in the camp for the long term, education is generally regarded as the only remaining hope to continue their everyday life. Hence, education is to give something more than a basic right-for 
example, learning how to read and write-as in other societies. Throughout their resettlement journey from home country to various host countries, education plays the role of increasing the consistency of their social and cultural identity. Despite this importance of education for ordinary people, various actors have different rationales for education, and this creates tensions both inside and outside the community. Although many global actors from outside the community seldom visit the field, they have long been adopting a rights-based approach to provide education programs based on the "medical model" (Waters and LeBlanc 2005). This is consistent with a UNHCR report finding that the critical reasons for supporting organized activities, such as education, early in an emergency context are to lessen the psychosocial impact of trauma and displacement and to protect at-risk groups (UNHCR 2003).

In a protracted camp setting, as in Mae La, educational curriculum and evaluation design is surrounded by questions of purpose that are often difficult to answer (McCarthy and Vickers 2012). What should education prepare children and young people for? Considering the durable solutions announced by the global actors, should education be used to prepare the refugee learners for repatriation, resettlement, or integration into the host country? Perhaps, we need to raise a question that is more practical, by considering this protractedness of the refugee context. What should education prepare children for, if they are prohibited from taking up employment in all the available societies around them? As the role of education for refugee children cannot be separated from the wider political environment, the rationale of schooling expressed by various actors in education policy and practice demonstrates whether the refugee situation is perceived as temporary or permanent. Under the unique environment that is set up as a temporary and liminal space outside the modern states, but gradually being perceived as a permanent one by the camp residents, persistent challenges are found as "unsettled" rationale for schooling that lead to inconsistent and mixed curriculum content. Figure 2 shows diverse actors which seem to have distinctive approaches, while they work actively in partnership to cater to the needs and rights of the refugee learners.

With the top-down development paradigm that perceives refugee education merely as a humanitarian relief effort, it is difficult to understand the dynamics of power in the structure of refugee education. Education for the refugees in the camp appears to be awkwardly structured by global governance, national jurisdiction, and local management. To adopt a post-development perspective, each and every actor involved in planning and providing refugee education must recognize the importance of communal interconnection and dialogue, and especially must respect and encourage grassroots actions.

Development projects are not sustainable. International NGOs only come for the projects and they leave when the projects end. KRCEE must look after it when they 
Figure 2. Diverse Actors and Approaches toward Education for Refugees

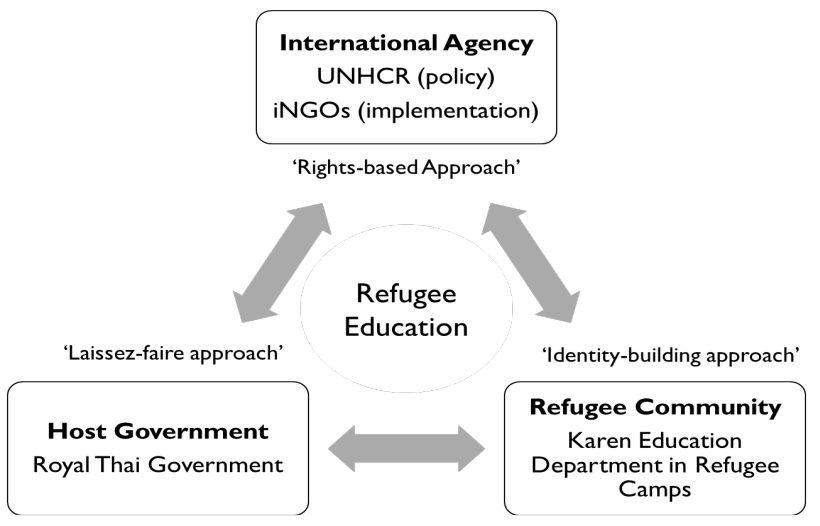

Source: Authors

leave. We are like ... parents without money. When the visitors come, they give you this and that. But when the visitors leave, the children ask why they are not getting what they used to get. It is not sustainable. If NGOs come, they have to consider working with the community based on what already exists, rather than creating something new and then leaving after the project ends without considering how it will affect the community afterwards. It is important to build the capacity of the locals (Interview with KRCEE Staff).

Bauman (1997; 2004) emphasizes how globalization along with forced migration-including that of refugees-has disrupted modern rights regimes, altering the form of the traditional nation-state. While the global actors still carry out the rights-based approach to education issues worldwide, tensions can easily be found between the exclusionary policies of education, that are mostly based on the logic of national citizenship, and the universal rights of children to education (Pinson and Arnot 2007). As the political theorist Benedict Anderson (2006) describes the modern nation as an "imagined community," the role of education in the Karen refugee camp is to provide each learner with a vision of their intellectual growth and a sense of their belonging. In other modern societies, the core function of schooling is to build citizenship and enable students to imagine themselves as part of a wider national community (Waters and LeBlanc 2005). Thus, in the context of Karen refugees in Thailand, the rationale of education needs to be critically questioned and further analyzed among the diverse education providers, as well as with the local stakeholders. If education is believed to play a critical role in helping refugee learners to imagine themselves as part of the wider community, a pragmatic question needs to be raised and discussed by all of the diverse stakeholders: what kind of "wider community" is left available for refugee learners? 


\section{Conclusion}

What eight years following a single group of displaced people shows is that the most pressing problem in camps for displaced people is not just physical suffering but existential disorder and profound uncertainty as well (Dunn 2017, 25).

To think of education as a right for refugee children-within the modern construction of citizenship-raises two vital questions: who can secure this right, and who is obliged to secure this right? Refugee children are exposed to significant gaps between the state and non-state systems in the rapidly changing and unstable architecture of global governance and support for national integration. Critical refugee studies scholar Yến Lê Espiritu (2016) argues that it is essential for scholars to disturb depoliticized narratives of refugeehood. She suggests that "another way to deploy refugee to make intelligible a wider set of problems is to consider how the refugee, who inhabits a condition of statelessness, radically calls into question the established principles of the nation-state [...] the original fiction of modern sovereignty" (ibid., 422). In this spirit, we have endeavoured to draw attention to the need for understanding the predicament of education in the particular context of a refugee camp community, where overlapping sources of authority operate with divergent visions and priorities for a stateless nation. In the protracted setting of Mae La refugee camp in Thailand, the students' lives in limbo have been perceived as neither permanent nor temporary under the "pseudo-state" that consists of a range of external stakeholders involved in providing refugee education. From the perspective of refugees themselves, we have also explored the uniqueness of education in the camp: how it is staffed by the refugees with a strong sense of imagined Karen nation rooted in Karen history and education, while being managed and funded by external others who advocate integration towards state systems. Under the traditional development paradigm, the idea of education is commonly understood to produce what is relevant for the market or what is to be consumed. Accordingly, the lack of a wider society and market for the camp residents results in the lack of consensus for both external and internal actors regarding the end goal of education for refugees. Coupled with a lack of accreditation, it leads to a crisis of meaning for schools, teachers and learners in the refugee camp while it is operating under the "pseudo-state" system.

To make refugee education more sustainable merely by attracting donor funds for continuation of the programs, many external actors continue to adopt a Eurocentric perspective by seeing education in its economic sense. Drawing on theories of post-development-while acknowledging the vast complexities that preclude any simple solutions-we suggest that it is essential to hear grassroots voices when conceptualizing and rationalizing education for the refugee learners. From Escobar's (2012; 2015) point of view, it is the community itself that sustains and continues to grow despite various challenging circumstances. Education 
in the Karen refugee camp demonstrates an attempt by refugee community members to learn to survive and govern their own system no matter what status they hold. The Karen education curriculum used in the camp today has been developed and sustained over a long period of time. The institutions that manage the education in the camp are structurally established while the community themselves also support and help to strengthen their own education which in turn generates a stronger identity. This is what Escobar puts forward: that a bottom-up approach to development makes the foundation stronger (Escobar $2010 ; 2012 ; 2015 ; 2018)$. This is supported by the Freirean critical perspective that the purpose of education is to conscientize learners about the existing oppressive system, and to invite active community participation in yearning for freedom. To have the refugee voices heard and to encourage refugee-centered participation, various stakeholders involved in providing education for refugees must develop a consensus. Building on insights from a Karen refugee community leader, a consensus is needed regarding the ways to bring freedom through a problemposing education.

The aim and objective of education is to safeguard fundamental human values. Within this framework, the act of education has to be focused on the humanizing of the marginalized, to promote changes, to sustain development, and to better meet the needs of the ever-changing human condition in the constantly progressing world. What's most important here is not safeguarding against boundaries, not inserting controls, but it is about freedom that leads to coordinated efforts towards, what Freire calls, a "problem-posing" lifestyle that supports positive social change. The world is not a motionless, static, compartmentalized and predictable fact. Thus, education has to be problem-posing in both content and delivery and has to counter the "colonizing forces" of authoritarian educators who do not encourage their students to challenge or confront social injustices, but to accept without question. Problem posing encourages students to perceive the world critically. Our world is not a "static reality" but is constantly undergoing an ever-changing process of transformation (Interview with Community Leader B).

We have here explored the characteristics and predicament of education in the refugee camp in the context of Karen refugees as members of a nation without a state. In conclusion, we suggest that the recent trend in refugee education, away from the global governance model and towards global support for national integration, may ultimately fall short in leading education to be transformative in the necessary ways. Without global support for local empowerment, and without explicitly addressing pressing existential questions (Dunn 2017,25) the system continues to place decision-making power in the hands of groups of people other than those directly affected. Acknowledging the protracted setting of the refugee crisis, we suggest that such an approach to education will ultimately fail to be liberating, in the Freirean sense, for those engaged in education. It keeps existing 
power structures intact, potentially even re-entrenching them, and does not address fundamental epistemological questions about to what ends education is pursued.

\section{Notes}

1. In this paper we use "Myanmar" to refer to the state formerly known as "Burma." We use "Burmese" to refer to the language and to the major ethnic group in Myanmar. However, in quotations from respondent interviews, we keep the terms actually used by the interviewees.

2. For a discussion of divergence between Burman-majority schools and refugee school accounts of history, see Metro 2012, 6 .

3. The Karen population within modern-day Karen State, which was established by the Myanmar government only in 1952, includes only a small portion of the total Karen population in the country (South 2011).

4. The exception is Karen Baptist Theological Seminary, established in 1845, which today not only serves seminary students but boasts one of the only liberal arts colleges in Myanmar.

5. This is not to diminish or hide the fact that strong Karen nationalism in the camp can also be oppressive for individuals, including Karen and members of other ethnic groups, and can hinder more nuanced or marginalized beliefs and identities.

\section{References}

ADRA. 2016. "Adventist Development and Relief Agency 2016 Annual Report.” https:// adra.org/wp-content/uploads/2014/08/ADRA-Annual-Report-2016_web.pdf (accessed November 18, 2019).

Anderson, Benedict. 2006. Imagined Communities: Reflections on the Origin and Spread of Nationalism. London and New York: Verso.

Bauman, Zygmunt. 1997. Postmodernity and its Discontents. New York: John Wiley \& Sons. Bauman, Zygmunt. 2004. Wasted lives: Modernity and its Outcasts. Cambridge: Polity Press. de Wal Pastoor, Lutine. 2016. "Rethinking Refugee Education: Principles, Policies and Practice from a European Perspective." In Annual Review of Comparative and International Education 2016. Emerald Group Publishing Limited, 107-16.

Dryden-Peterson, S. 2016. "Refugee Education in Countries of First Asylum: Breaking Open the Black Box of Pre-resettlement Experiences." Theory and Research in Education 14 (2): 131-48.

Dryden-Peterson, S. 2017. "Refugee Education: Education for an Unknowable Future." Curriculum Inquiry 47 (1): 14-24.

Dunn, Elizabeth Cullen. 2017. No Path Home: Humanitarian Camps and the Grief of Displacement. Ithaca, NY: Cornell University Press.

Escobar, Arturo. 2010. "Latin America at a Crossroads: Alternative Modernizations, PostLiberalism, or Post-Development?” Cultural Studies 24 (1): 1-65. 
Escobar, Arturo. 2012. Encountering Development: The Making and Unmaking of the Third World. Princeton: Princeton University Press.

Escobar, Arturo. 2015. "Degrowth, Postdevelopment, and Transitions: A Preliminary Conversation." Sustainability Science 10 (3): 451-62.

Escobar, Arturo. 2018. Designs for the Pluriverse: Radical Interdependence, Autonomy, and the Making of Worlds. Durham: Duke University Press.

Espiritu, Yến Lê. 2016. "Toward a Critical Refugee Study: The Vietnamese Refugee Subject in US Scholarship." Journal of Vietnamese Studies 1 (1-2): 410-33.

Falk, Richard A. 2015. Humanitarian Intervention and Legitimacy Wars: Seeking Peace and Justice in the 21st Century. New York: Routledge.

Ferguson, James. 1994. The Anti-Politics Machine: Development, Depoliticization and Bureaucratic Power in Lesotho. Minneapolis: University of Minnesota Press.

Ferguson, Jane. 2014. “The Scramble for the Waste Lands: Tracking Colonial Legacies, Counterinsurgency and International Investment through the Lens of Land Laws in Burma/Myanmar." Singapore Journal of Tropical Geography 35 (3): 295-311.

Fink, Christina. 2009. Living Silence in Burma: Surviving under Military Rule, 2nd ed. Chiang Mai: Silkworm Books.

Freire, Paulo. 1996. Pedagogy of the Oppressed. New York: Penguin Books.

Freire, Paulo. 2004. Pedagogy of Indignation. Boulder: Routledge.

Jones, P. W., and D. Coleman. 2005. The United Nations and Education: Multilateralism, Development and Globalization. London; New York: Routledge Falmer.

Kelley, N., P. Sandison, and S. Lawry-White. 2004. Enhancing UNHCR's Capacity to Monitor the Protection, Rights and Well-being of Refugees. Geneva: UNHCR.

KRCEE (Karen Refugee Committee Education Entity). 2008. Quarterly Report. Mae Sot District, Thailand: KRCEE

KRCEE (Karen Refugee Committee Education Entity). 2019. Quarterly Report. Mae Sot District, Thailand: KRCEE.

Lee, Sang Kook. 2007. "Integrating Others: In the Thailand-Burma Borderland.” National University of Singapore.

McCarthy, Florence. E., and Margaret H. Vickers. 2012. Refugee and Immigrant Students: Achieving Equity in Education. Information Age Publishing.

Metro, Rosalie. 2006. Developing History Curricula to Support Multi-ethnic Civil Society Among Burmese Refugees and Migrants. Geneva: UNHCR.

Metro, Rosalie. 2012. "Postconflict History Curriculum Revision as an 'Intergroup Encounter' Promoting Interethnic Reconciliation among Burmese Migrants and Refugees in Thailand." Comparative Education Review 57 (1): 145-68.

OCEE (Office of Camp Education Entity). 2019. Quarterly Report. Mae Sot District, Thailand: OCEE.

Oh Su-Ann. 2011. "Education in Refugee Camps in Thailand: Policy, Practice and Paucity." Education for All Global Monitoring Report. Paris: UNESCO.

Perkins, Carrie. 2019. "Rethinking Repatriation: Karen Refugees on the Thai-Myanmar Border." Ph.D. diss. (unpubilshed). Southern Methodist University, Dallas, Texas.

Pinson, Halleli, and Madeleine Arnot. 2007. "Sociology of Education and the Wasteland of Refugee Education Research.” British Journal of Sociology of Education 28 (3): 399407.

Pwe, Naw Say Say. 2018. “The Beginning of Karen Education in Irrawaddy Division during 
the British Colonial Period." Journal of Humanities and Social Sciences 46 (1): 221-38.

Rebecca, Naw. 1989. "Karen Education: Children on the Front Line." Cultural Survival, Child Survival Quarterly 13 (4): 30-31.

Ruggie, John Gerald. 2003. "The United Nations and Globalization: Patterns and Limits of Institutional Adaptation." Global Governance 9 (3): 301-21.

Shiva, V., A Jafri, A. Emani, S. Bhutani, and U. Prasad. 2000. Licence to Kill: How the Unholy Trinity-The World Bank, The International Monetary Fund, and The World Trade Organization-Are Killing Livelihoods, Environment, and Democracy in India. New Delhi: Research Foundation for Science, Technology, and Ecology.

Simpson, Audra. 2014. Mohawk Interruptus: Political Life Across the Borders of Settler States. Durham: Duke University Press.

Smith, Martin J. 1999. Burma: Insurgency and the Politics of Ethnicity. New York: Zed Books.

South, Ashley. 2011. Burma's Longest War: Anatomy of the Karen Conflict. Amsterdam: Transnational Institute.

South, Ashely, and Marie Lall. 2016. Schooling and Conflict: Ethnic Education and Mother Tongue-Based Teaching in Myanmar. Yangon: The Asia Foundation.

Stevenson, Lisa. 2014. Life Beside Itself: Imagining Care in the Canadian Arctic. Oakland: University of California Press.

TBC (The Border Consortium). 2019. The Border Consortium (TBC) Monthly Population Report October 2019. Mae Sot District, Thailand: TBC

Thant, Myint-U. 2001. The Making of Modern Burma. Cambridge: Cambridge University Press.

UN (United Nations). 1989. Convention on the Rights of the Child. New York: UN.

UNESCO (United Nations Educational, Scientific and Cultural Organization). 2018. Paper Commissioned for the 2019 Global Monitoring Report, Migration, Displacement and Education: Building Bridges, Not Walls. Paris: UNESCO.

UNESCO (United Nations Educational, Scientific and Cultural Organization) and UNHCR (United Nations High Commissioner for Refugees). 1984. Memorandum of Understanding between UNESCO and UNHCR on Education for Refugees. Paris, France: UNESCO.

UNHCR (United Nations High Commissioner for Refugees). 1988. Organizing Primary Education for Refugee Children in Emergency Situations: Guidelines for Field Managers. Geneva: UNHCR.

UNHCR (United Nations High Commissioner for Refugees). 2003. Education Field Guidelines. Geneva, Switzerland: UNHCR.

UNHCR (United Nations High Commissioner for Refugees). 2009. Refugee Education in Urban Settings: Case Studies from Nairobi - Kampala - Amman - Damascus. Geneva: UNHCR.

UNHCR (United Nations High Commissioner for Refugees). 2010. Refugee Education in Urban Settings. Geneva: UNHCR.

UNHCR (United Nations High Commissioner for Refugees). 2012. Education Strategy 2012-2016. Geneva: UNHCR.

Verdirame, Guglielmo, and Barbara E. Harrell-Bond. 2005. Rights in Exile: Janus-faced Humanitarianism. New York: Berghahn Books.

Waters, Tony, and Kim LeBlanc. 2005. "Refugees and Education: Mass Public Schooling 
without a Nation-state." Comparative Education Review 49 (2): 129-47.

World Education. 2016. School Committees and Community Engagement in Education in Karen State. Mae Sot, Thailand: World Education.

Subin Sarah Yeo is a Ph.D. candidate in the Department of Global Education Cooperation at Seoul National University, South Korea. She is currently writing her dissertation entitled "Reconceptualizing Refugee Education: Education For, Of, and By Refugees in a Karen Refugee Camp, Thailand." She is a former primary school teacher from Australia, where she worked with students of refugee backgrounds.Email: sarah5430@snu.ac.kr.

Terese Gagnon is a Ph.D. candidate in anthropology at Syracuse University, Syracuse, New York, U.S. where she is currently writing her dissertation entitled "Hungering for Freedom: Sensory Politics and Biodiversity for Karen in Exile." Email: tvgagnon@syr.edu.

Hayso Thako is a Ph.D. candidate at the Department of Peacebuilding, Payap University, Thailand. Currently, he is Education \& Livelihood Coordinator at Karen Refugee Committee, Chair/Executive Director at Karen Peace Support Network, and Deputy Director at Asia-Pacific Network of Refugees. Email: hayso2008@gmail.com.

Submitted: December 2, 2019; Revised: March 23, 2020; Accepted: March 31, 2020 